\title{
First record of a wilt disease of banana plants associated with phytoplasmas in Solomon Islands
}

\author{
R. I. Davis ${ }^{1}$ - J. Henderson ${ }^{2,3}$ - L. M. Jones ${ }^{1}$ - A. R. McTaggart ${ }^{4}$ •

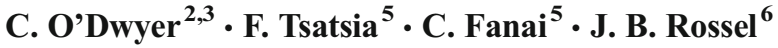

Received: 8 February 2015 / Accepted: 18 March 2015 /Published online: 14 April 2015

(C) Australasian Plant Pathology Society Inc. 2015

\begin{abstract}
Phytoplasmas were detected by nested and real time PCR from wilted cooking banana plants in Solomon Islands close to the border with Papua New Guinea (PNG). These phytoplasmas and two similar phytoplasmas found adjacent in PNG formed a group from the Solomon Island archipelago indistinguishable from each other by sequence analysis. These and similar phytoplasmas from the island of New Guinea were most closely related to phytoplasmas in the16SrXXII-A group.
\end{abstract}

R. I. Davis

richard.davis@agriculture.gov.au

1 Department of Agriculture, Northern Australia Quarantine Strategy (NAQS), PO Box 96, Cairns International Airport, Cairns, Qld 4870, Australia

2 Queensland Alliance for Agriculture and Food Innovation (QAAFI), The University of Queensland, Brisbane, Qld 4072, Australia

3 Queensland Department of Agriculture and Forestry (QDAF), PO Box 267, Brisbane, Qld 4001, Australia

4 Department of Microbiology and Plant Pathology, Tree Protection Co-operative Programme (TPCP), Forestry and Agricultural Biotechnology Institute (FABI), University of Pretoria, Private Bag X20, Pretoria 0028, South Africa

5 Biosecurity Solomon Islands, Ministry of Agriculture and Livestock, PO Box G13, Honiara, Solomon Islands

6 Department of Agriculture, International Plant Health Program, GPO Box 858, Canberra City ACT 2601, Australia
Keywords Phytoplasma · Musa sp · Wilt disease · Solomon Islands

In February 2012, a plant health survey was conducted in Solomon Islands close to the border with Papua New Guinea (PNG) by Biosecurity Solomon Islands (BSI) and the International Plant Health Program of Australia's Department of Agriculture. The survey focused on key areas lying adjacent to PNG's North Solomons Province (NSP), also called the autonomous region of Bougainville. These were the western end of Choiseul Island and Taro Island, in Choiseul Province; certain islands in the Shortland Islands group; Mono Island and certain islands in the New Georgia Group, Western Province. Geographically, NSP and most of the islands that comprise the country known as Solomon Islands make up the Solomon Islands archipelago.

On Maleai Island, Shortland Islands group, a severe wilt disease of cooking banana plants (ABB genome) was widespread. The plants showed yellowing and/or leaf death (Fig. 1) and unfilled fruit bunches. No evidence of corm borers, corm or root rots, sheath rots, or excessive nematode damage was seen. Internal pseudostem tissue did not show symptoms of the biosecurity target diseases fusarium wilt (Moore et al. 1995) and bacterial wilt (Eden-Green 1994). Instead, the symptoms found inside were identical to those of a disease recently described in PNG, associated with a phytoplasma that may represent a new 'Candidatus Phytoplasma' species (Davis et al. 2012). These are discontinuous brown or black vascular streaks (1-several $\mathrm{cm}$ only) associated with wet, necrotic pockets (Fig. 2). 


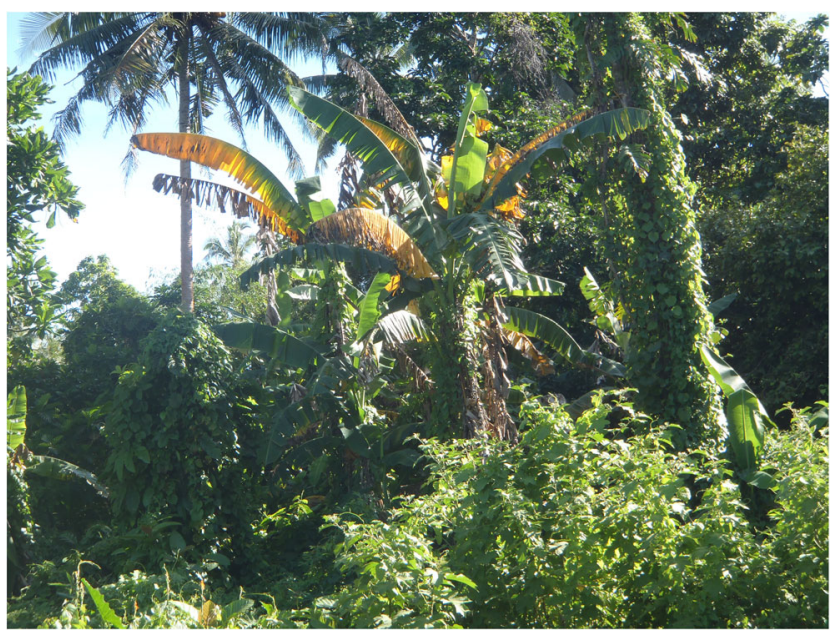

Fig. 1 External symptoms (leaf yellowing and leaf death) associated with phytoplasmas in cooking banana plants growing on Maleai Island

Three affected plants were sampled as described by Davis et al. (2012). A search for symptomless plants of the same genotypes was made to help determine if phytoplasmas were associated only with the wilt symptoms, rather than occurring only as incidental infections. However, no unaffected identical stands could be found, so symptomless examples of a different $\mathrm{ABB}$ cooking banana plant on Maleai Island and one of the affected genotypes on adjacent Shortland Island were sampled (details provided in Table 1).

DNA was extracted from the samples in the BSI laboratory in Honiara as described in Davis et al. (2012) and were returned to the Department of Agriculture

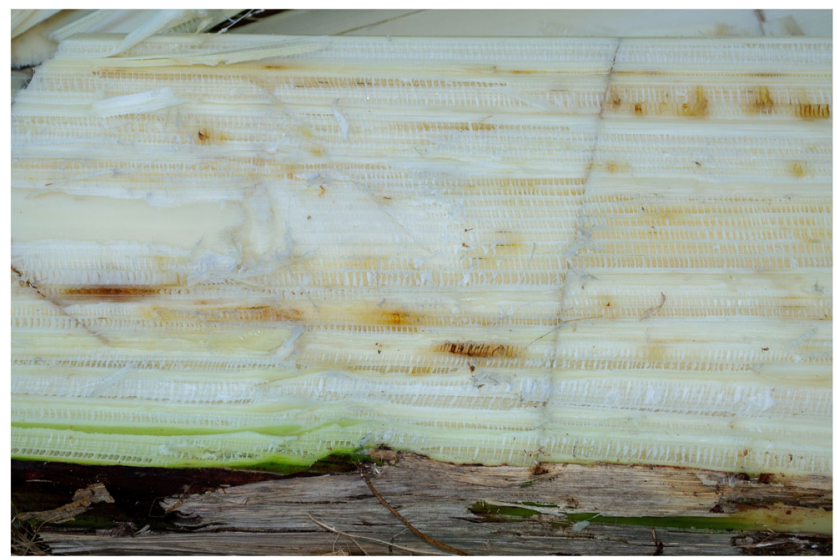

Fig. 2 Internal symptoms shown by sample 6350: discontinuous necrotic vascular streaks and pockets of rot and discolouration laboratory in Cairns, Australia where they were tested for phytoplasma by nested PCR using the P1/P7 primer pair for first round and the R16F2n / m23SR primer pair for second round as described by Constable et al. (2003). The three symptomatic banana plant extracts tested positive and the two control extracts, which amplified with 16S rRNA gene internal control primers, indicating good PCR integrity, tested negative (Table 1). For verification, the three symptomatic plant extracts also tested positive in a Queensland Department of Agriculture and Forestry laboratory using the universal phytoplasma real-time PCR method of Hodgetts et al. (2009). This is based on the 23S rRNA gene and used forward primers, JH-F 1, JH-F all; reverse primer, JH-R; probe JH-P uni.

Products from the second round of nested PCR amplification (R16F2n / m23SR primer pair) were cloned and sequenced for two of the three positive isolates (RID 6348 and RID 6350). PCR products were cloned directly without purification using the $\mathrm{TOPO}^{\circledR} \mathrm{TA}$ Cloning Kit for Sequencing and One Shot ${ }^{\circledR}$ TOP10 Chemically Competent E. coli according to the manufacturer's protocol (Life Technologies). Transformants were prepared using the Purelink ${ }^{\mathrm{TM}}$ Quick Plasmid Miniprep Kit (Life Technologies) and screened by EcoRI digestion. Cloned products were sequenced using M13 forward and reverse primers and the BigDye $^{\mathrm{TM}}$ Terminator v3.1 Cycle Sequencing Kit (Life Technologies). Phytoplasmas have been found in diseased cooking banana plants in PNG's NSP (Davis et al. 2012). One of these from Bougainville Island (RID 5989) and one from Buka Island (RID 5861) were also cloned and sequenced as described above to determine relatedness between the two groups. A similar phytoplasma from PNG's Western Province (RID5838, Davis et al. 2012) was also cloned and sequenced as above for comparison. The 16S rRNA gene sequences of the five phytoplasma isolates, RID 5838, 5861, 5989, 6348, and 6350, were deposited in GenBank as KP642659 KP642663, respectively.

rRNA gene sequences of these phytoplasmas plus one from Madang Province, PNG (GenBank accession No. JN872863 Banana wilt associated phytoplasma, BWAP), were analysed using the $i$ Phyclassifier program of Zhao et al. (2009). None matched any known patterns sufficiently for assignment to any known group/subgroup and the most similar patterns belonged to three different phytoplasmas associated with coconut lethal yellowing diseases (Table 2). Phylogenetic analysis of the $16 \mathrm{~S}$ rRNA gene using 44 phytoplasma species / strains (Wei et al. 2007, http://plantpathology.ba.ars.usda.gov/pclass/ pclass_phytoplasmaclassification_system 2.html, Kelly 
Table 1 Details of cooking banana samples collected in the Solomon Islands

\begin{tabular}{lllll}
\hline Collection no. & Local name & Location & Symptoms $^{\text {a }}$ & Nested PCR test result \\
\hline 6348 & Vovosi & Maleai Is. & Yellowing and leaf death and DNV & + \\
6350 & Vovosi & Maleai Is. & Yellowing and DNV & + \\
6351 & Sauhu & Maleai Is. & Yellowing & + \\
6352 & Samarai & Maleai Is. & Slight leaf chlorosis only & - \\
6349 & Vovosi & Shortland Is. & None & - \\
\hline
\end{tabular}

${ }^{a} D N V$ discontinuous necrotic vascular tissue et al. 2011, plus additional palm phytoplasmas) was conducted using two phylogenetic criteria, maximum likelihood in RAxML (Stamatakis 2014), and Bayesian Inference in Mr Bayes (Ronquist and Huelsenbeck 2003) (Fig. 3). GTRGAMMA was specified as the model of evolution for both criteria. In the phylogenetic analyses, the isolates of phytoplasma from banana plants were recovered in a monophyletic group with the phytoplasma associated with lethal yellowing like symptoms in coconuts in PNG (GQ227853 Cocos nucifera lethal yellowing phytoplasma, Kelly et al. 2011). The four isolates from the Solomon Islands archipelago had identical sequences and this group was sister to BWAP, RID 5838, and Cocos nucifera lethal yellowing phytoplasma. 'Candidatus Phytoplasma cocosnigeriae', previously known as the Awka wilt phytoplasma, a member of the Nigerian coconut lethal decline (LDN) group, was sister to the phytoplasmas in banana plants in PNG / Solomon
Islands and Cocos nucifera lethal yellowing phytoplasma. LDN phytoplasmas have caused severe coconut disease epidemics in Nigeria and Ghana (Tymon et al. 1998). The Awka wilt phytoplasma has been reassigned from the 16SrIV group to 16SrXXII-A (Wei et al. 2007). More recently, this phytoplasma was shown to be identical to the reference strain of the proposed novel taxon, 'Candidatus Phytoplasma palmicola' within the 16SrXXII-A sub group (Harrison et al. 2014).

The geographic locations of the phytoplasmas studied are depicted in Fig. 4. Our results indicate phytoplasmas on banana plants and coconut trees in these islands diversified from a recent common ancestor. The different phytoplasmas on similar hosts separated by geography may be a result of allopatric speciation. Cocos nucifera lethal yellowing phytoplasma (GQ227853) has a partial sequence of $16 \mathrm{~S}$ rRNA gene $(756 \mathrm{bp})$ that is identical to BWAP (JN872863). This relationship may be the

Table 2 Closest phytoplasma comparisons obtained using the $i$ Phyclassifier program

\begin{tabular}{|c|c|c|c|c|c|}
\hline Phytoplasma & Location & $\begin{array}{l}\text { GenBank accession No. of } \\
\text { most similar reference pattern }\end{array}$ & $\begin{array}{l}\text { 16Sr subgroup of most } \\
\text { similar reference pattern }\end{array}$ & $\begin{array}{l}\text { Corresponding name of most } \\
\text { similar reference pattern }\end{array}$ & $\begin{array}{l}\text { Similarity } \\
\text { coefficient }\end{array}$ \\
\hline JN872863 & Furan, PNG & X80117 & 16Sr group IV-C & 'Ca. P. cocostanzaniae' & 0.74 \\
\hline RID5838 & Debepari PNG & Y14175 & $16 \mathrm{Sr}$ group XXII-A & 'Ca. P. cocosnigeriae' & 0.77 \\
\hline RID5861 & Buka, PNG & Y14175 & $16 \mathrm{Sr}$ group XXII-A & 'Ca. P. cocosnigeriae' & 0.68 \\
\hline RID5989 & $\begin{array}{l}\text { Bougainvile, } \\
\text { PNG }\end{array}$ & X80117 & 16Sr group IV-C & 'Ca. P. cocostanzaniae' & 0.65 \\
\hline RID6348 & $\begin{array}{l}\text { Maleai, Solomon } \\
\text { Islands }\end{array}$ & Y14175 & $16 \mathrm{Sr}$ group XXII-A & 'Ca. P. cocosnigeriae' & 0.68 \\
\hline RID6350 & $\begin{array}{l}\text { Maleai, Solomon } \\
\text { Islands }\end{array}$ & AF498307 & 16Sr group IV-A & $\begin{array}{l}\text { Coconut lethal yellowing } \\
\text { phytoplasma strain Jamaica }\end{array}$ & 0.67 \\
\hline
\end{tabular}

${ }^{a}$ The 16SrRNA gene sequences from the phytoplasmas found in banana plants in the Solomon Islands archipelago (RID5861, 5989, 6348 and 6350), as well as the two from the Island of New Guinea (JN872863, BWAP; RID 5838), were analysed using the $i$ Phyclassifier program of Zhao et al. (2009). This program compared virtual RFLP patterns derived from the 16S rRNA gene F2nR2 regions with reference patterns from all previously established $16 \mathrm{Sr}$ groups/subgroups. None matched any known patterns, and all similarity coefficients to the most similar pattern were below 0.85 , the cut off point for group/subgroup assignment (Zhao et al. (2009) 


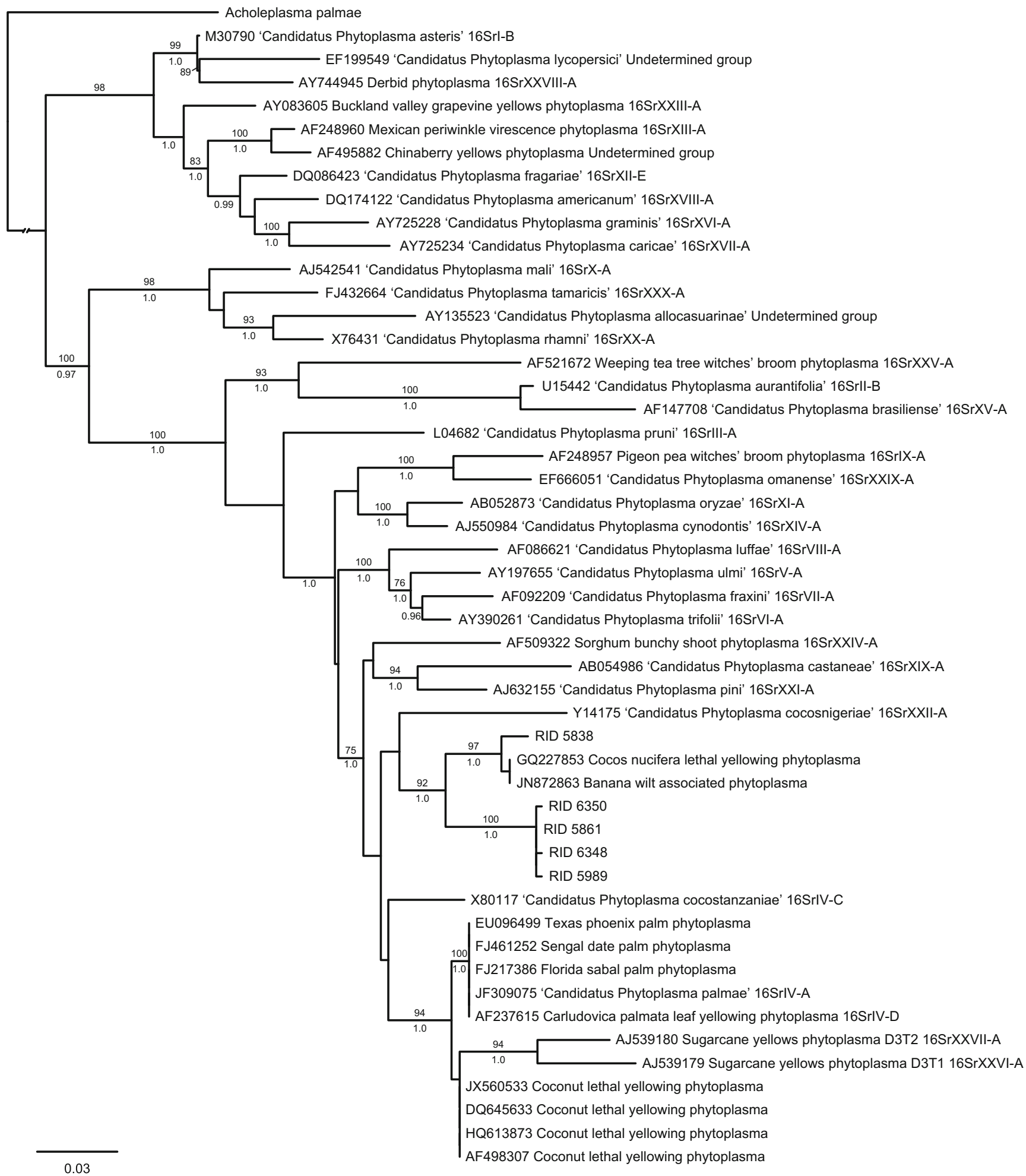

Fig. 3 Phylogram recovered from a maximum likelihood search in RAxML with an alignment of the 16S rDNA region. Bootstrap values $(\geq 70 \%$ ) from 1000 bootstrap replicates shown above nodes. Posterior

result of a host jump from banana plant to coconut tree, however, a different systematic relationship may be recovered with the full $16 \mathrm{~S}$ rRNA gene sequence. probability values $(\geq 0.95)$ from a Bayesian analysis in MrBayes summarized from 30,000 converged trees in 4 runs with 4 chains shown below the nodes

The available evidence suggests that this phytoplasma is not widespread in Solomon Islands. No such symptoms were seen elsewhere on this survey or on four similar surveys of 


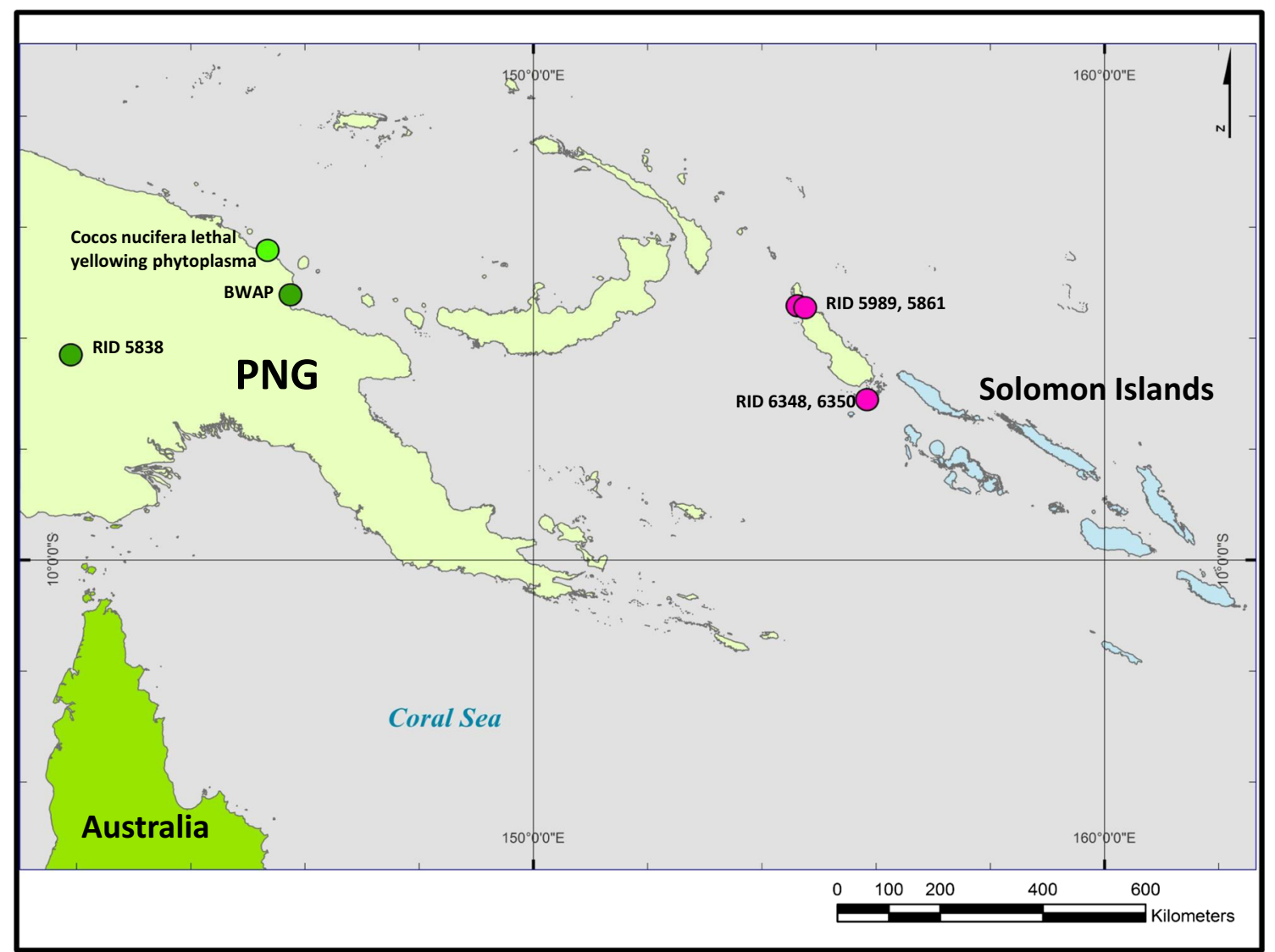

Fig. 4 Map of the region with Australia's Cape York Peninsula in green, Papua New Guinea (PNG) in light green, and Solomon Islands in light blue. The approximate locations of the phytoplasmas included in the phylogenetic analysis are indicated by coloured circles: pink for the

different regions of the country conducted in 2007, 2010, 2011 and 2014 (BSI unpublished data). Internal quarantine containment is strongly recommended. In particular, the movement of banana planting material from the Shortland Islands should be prohibited.

More studies on the diversity of phytoplasmas associated with banana wilt disease are planned. Further phylogenetic comparisons between phytoplasmas from diseased banana plants and coconut trees in PNG are also needed because the limited data available leaves it unclear whether these two important monocotyledonous crop diseases are associated with the same or different phytoplasmas.

Acknowledgments Funding was provided by the Solomon Island Biosecurity Development Program, which is managed by the Department of Agriculture and funded by the Department of Foreign Affairs and Trade. Tim Kerlin, NAQS, Department of Agriculture, is gratefully thanked for preparing Fig. 4.

Conflict of interest The authors declare that they have no conflict of interest. sister group of phytoplasmas from banana plants in the the Solomon Islands archipelago and green for the sister group of phytoplasmas from banana plants and one coconut tree in PNG

\section{References}

Constable FE, Gibb KS, Symons RH (2003) Seasonal distribution of phytoplasmas in Australian grapevines. Plant Pathol 52: 267-276

Davis RI, Kokoa P, Jones LM, Mackie J, Constable FE, Rodoni BC, Gunua TG, Rossel JB (2012) A new banana wilt disease associated with phytoplasmas in Papua New Guinea. Australas Plant Dis Notes 7:91-97

Eden-Green SJ (1994) Banana blood disease. Musa disease fact sheet No. 3. INIBAP, Montpellier, $2 \mathrm{p}$

Harrison NA, Davis RE, Oropeza C, Helmick EE, Narváez M, EdenGreen S, Dollet M, Dickinson M (2014) 'Candidatus Phytoplasma palmicola', associated with a lethal yellowing-type disease of coconut (Cocos nucifera L.) in Mozambique. Int J Syst Evol Microbiol 64:1890-1899

Hodgetts J, Boonham N, Mumford R, Dickinson M (2009) Panel of 23S rRNA gene-based real-time PCR assays for improved universal and group-specific detection of phytoplasmas. Appl Environ Microbiol 75:2945-2950

Kelly PL, Reeder R, Kokoa P, Arocha Y, Nixon T, Fox A (2011) First report of a phytoplasma identified in coconut palms (Cocos nucifera) with lethal yellowing-like symptoms in Papua New Guinea. New Dis Rep 23:9

Moore NY, Bentley S, Pegg KG, Jones DR (1995) Fusarium wilt of banana. Musa disease fact sheet No. 5. INIBAP, Montpellier, $4 \mathrm{p}$ 
Ronquist F, Huelsenbeck JP (2003) MrBayes 3: bayesian phylogenetic inference under mixed models. Bioinformatics 19:1572-1574

Stamatakis A (2014) RAxML version 8: a tool for phylogenetic analysis and post-analysis of large phylogenies. Bioinformatics. doi:10.1093/ bioinformatics/btu033

Tymon AM, Jones P, Harrison NA (1998) Phylogenetic relationships of coconut phytoplasmas and the development of specific oligonucleotide PCR primers. Ann Appl Biol 132:37-452
Wei W, Davis RE, Lee I-M, Zhao Y (2007) Computer-simulated RFLP analysis of 16S rRNA genes: identification of ten new phytoplasma groups. Int J Syst Evol Microbiol 57:1855-1867

Zhao Y, Wei W, Lee I-M, Shao J, Suo X, Davis RE (2009) Construction of an interactive online phytoplasma classification tool, $i$ Phyclassifier, and its application in analysis of the peach $\mathrm{X}$ disease phytoplasma group (16SrIII). Int J Syst Evol Microbiol 59: 2582-2593 